\title{
Neutropenic Enterocolitis Associated with Docetaxel-based Chemotherapy in a Patient with Breast Carcinoma
}

\author{
Haldun Kar, Necat Cin, Özgün Akgül, Cengiz Tavusbay, Yasin Peker, Fatma Tatar \\ Department of General Surgery, Katip Çelebi University Atatürk Training and Research Hospital, İzmir, Turkey
}

\begin{abstract}
Introduction: Neutropenic enterocolitis (NE) is a rare but often life-threatening complication associated with taxane-based chemotherapy in patients with cancer.

Case Report: A 39-year-old woman with a diagnosis of breast carcinoma underwent breast conserving surgery for the right breast. She was treated with docetaxel, cyclophosphamide, and epirubicin for the following months. Seven days after receiving the first dose of chemotherapy, she was presented to our emergency center with diarrhea, vomiting, fever, and diffuse abdominal pain. Abdominal examination revealed right lower quadrant tenderness with rebound. Blood work revealed severe neutropenia and leucopenia. Computed tomography demonstrated thickening of the walls of the ascending and transverse colon. Furthermore, emergency laparotomy revealed a necrotic hepatic flexura without perforation. Right hemicolectomy was performed; the biopsy revealed acute hemorrhagic infarction of the colon.
\end{abstract}

Conclusion: Patients with breast carcinoma presenting with acute abdominal pain, neutropenia, and radiologically demonstrable bowel wall thickening while receiving taxane-based chemotherapy should be suspected of having NE.

Keywords: Neutropenic enterocolitis, docetaxel, chemotherapy

Received:05.10.2015 Accepted: 14.11.2015 Available Online Date: 04.02.2016

\section{Introduction}

Neutropenic enterocolitis (NE) is a clinical syndrome that can occur because of neutropenia induced by a disease or chemotherapy (1). It is mostly reported in adults with leukemia. Although the true incidence of the disease is unknown, it is estimated that $5 \%$ of adults undergoing chemotherapy for solid malignant tumors suffer from NE $(1,2)$. Docetaxel is a well-known taxanebased drug with high antitumor activity in different solid tumors. NE is reported as a life-threatening complication in patients receiving taxane-based anticancer drugs. Mortality rates are reported between 30 and 50\%, mostly because of colon perforation and uncontrolled sepsis. Early diagnosis and immediate appropriate therapy affect the clinical outcome of NE $(3,4)$ We report a case of surgically treated NE in a patient who underwent docetaxel therapy for breast cancer.

\section{Case Report}

A 39-year-old woman with a diagnosis of breast carcinoma underwent breast conserving surgery for the right breast. Her past medical history explained that pathological examinations of the specimen revealed invasive ductal carcinoma, positive axillary lymph nodes, negative for estrogen and progesterone receptors and positive for C-erb B2. In this case of T1N1M0 breast cancer, she was treated with docetaxel $\left(100 \mathrm{mg} / \mathrm{m}^{2}\right)$, cyclophosphamide $\left(650 \mathrm{mg} / \mathrm{m}^{2}\right)$, and epirubicin $\left(100 \mathrm{mg} / \mathrm{m}^{2}\right)$ for the following months. Seven days after receiving the first dose of chemotherapy, she was presented to our emergency center with a $24 \mathrm{~h}$ history of diarrhea, vomiting, fever, and diffuse abdominal pain. On physical examination, her blood pressure was 90/50 $\mathrm{mmHg}$, pulse rate was $100 / \mathrm{min}$, and temperature was $38.9^{\circ} \mathrm{C}$. Examination of the abdomen showed right lower quadrant tenderness with rebaund and rigidity. A blood sample examination revealed severe neutropenia $\left(0.164 \times 10^{9} / \mathrm{L}\right)$ and leucopenia 


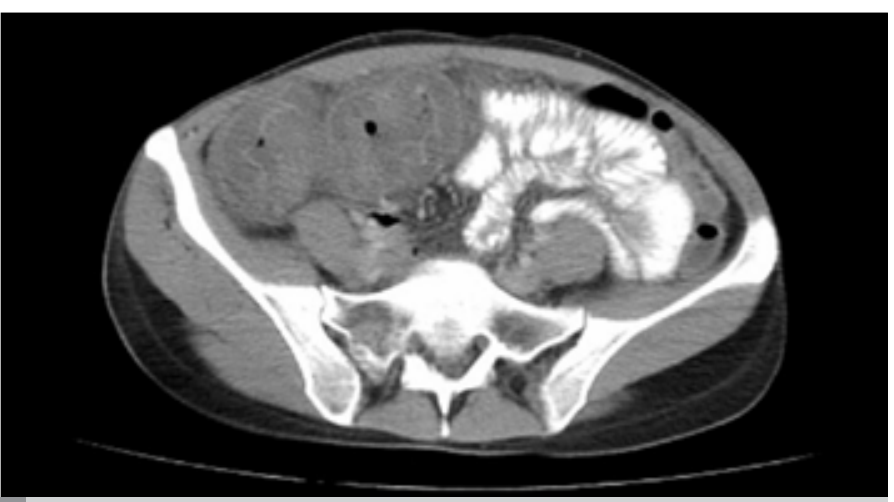

FIGURE 1. Abdominal CT scan showing bowel wall thickening (ascending and transverse colon)

$\left(0.667 \times 10^{9} / L\right)$. Computed tomography (CT) demonstrated thickening of the walls of the ascending and transverse colon as well as fluid and inflammatory changes in the pericolonic soft tissue (Figure 1). Based on these results, the patient was hospitalized. Medical treatment were started. Twenty-four hours after investigation, she underwent emergency exploratory laparotomy and revealed a necrotic hepatic flexura without perforation. The bowel wall appeared to be thickened and surrounded the omentum majus. Right hemicolectomy and ileotransversostomy were performed. Biopsy revealed acute hemorrhagic infarction of the colon. The patient recovered well and was discharged after 6 days. Chemotherapy was continued with the same regime but a reduced dose. At the 4-year follow-up, the patient was doing well with no recurrences.

\section{Discussion}

Docetaxel is a well-known taxane-based drug with high antitumor activity in different solid tumors, particularly in breast cancer (5). Recent reports suggest that NE is associated with taxanes. Although NE can occur after intensive docetaxel as a single therapy, it is mostly reported that the incidence is higher when conjugated with other microtubule targeting agents such as vinorelbine and cyclophosphamide $(3,6,7)$. NE could occur after any cycle of the chemotherapy regimen (1).

NE is a clinical syndrome characterized by fever, abdominal pain, and diarrhea within 7-10 days following a chemotherapy course. Because the clinical manifestations are nonspecific, the differential diagnosis is wide, including Clostridium difficile associated colitis. The disease may involve any segment of the gastrointestinal tract with a predilection of the ileocecal area due to the poor vascularity of that segment (3). Radiologic imaging is helpful in differential diagnosis. Bowel wall thickening demonstrated using CT or ultrasonography is one of the main proposed criteria to establish diagnosis and seems to be predictive of prognosis. Moreover, bowel wall thickening (>10 $\mathrm{mm}$ ) is reported to be related to severe disease and a worse prognosis $(3,6,8)$. Colonoscopy is not recommended because of a high risk of intestinal perforation $(3,8)$. Pathologically, the disease is caused by mucosal damage of the bowel, bacterial invasion, increased bacterial proliferation due to decreased immunocompetence, production of bacterial endotoxin, intramural hemorrhage, ulceration, ischemia, and in some cases necrosis leading to perforation $(7,9)$.
Although the management of NE is controversial, most authors recommend conservative therapy until maintaining normal neutrophil counts. Medical therapy includes bowel rest, intravenous fluids, parenteral nutrition, and broad-spectrum antibiotics. Patients should be closely monitored during the medical treatment and even following discharge because of the risk of relapse. Surgery is indicated in cases with peritonitis, persistent gastrointestinal bleeding, and clinical worsening despite aggressive medical therapy $(3,6,8)$. Laparotomy should be delayed, if possible, until the absolute neutrophil count returns to normal (10).

\section{Conclusion}

Patients with breast carcinoma presenting with acute abdominal pain, neutropenia, and radiologically demonstrable bowel wall thickening under taxane-based chemotherapy should be suspected of NE because half of the patients are reported to have a fatal outcome in case of a diagnostic delay. Therefore, surgeons should gain more knowledge related NE to start prompt surgical therapy when appropriate.

Informed Consent: Written informed consent was obtained from patient who participated in this case.

Peer-review: Externally peer-reviewed.

Author Contributions: Concept - H.K.; Design - N.C.; Supervision - F.T., Y.P.; Materials - Ö.A.; Data Collection and/or Processing - H.K., C.T.; Analysis and/ or Interpretation - H.K.; Literature Review - N.C.; Writer - H.K.; Critical Review - F.T., C.T.

Conflict of Interest: The authors declared no conflict of interest.

Financial Disclosure: The authors declared that this study has received no financial support.

\section{References}

1. Li Z, Ibrahim NK, Wathen JK, Wang M, Mante Menchu RP, Valero V, et al. Colitis in patients with breast carcinoma treated with taxane-based chemotherapy. Cancer 2004; 101: 1508-13. [CrossRef]

2. Rolston KV. Neutropenic Enterocolitis Associated with Docetaxel Therapy in a Patient with Breast Cancer. Clin Adv Hematol Oncol 2009; 7: 527-8.

3. Nesher L, Rolston KV. Neutropenic Enterocolitis, a growing concern in the era of widespread use of aggressive chemotherapy. Clin Infect Dis 2013; 56: 711-7. [CrossRef]

4. Ullery BW, Pieracci FM, Rodney JRM, Barie PS. Neutropenic Enterocolitis. Surg Infect (Larchmt) 2009; 10: 307-14. [CrossRef]

5. Hussein MA, Bird BR, O'Sullivan MJ, Kalimuthu SG, O'Sullivan GC, O'Reilly S et al. Symptoms in cancer patients and an unusual tumor: Case 2. Docetaxelrelated ischemic colitis. J Clin Oncol 2005; 23: 9424-5. [CrossRef]

6. Dumitra S, Sideris L, Leclerc Y, Leblanc G, Dube P. Neutropenic enterocolitis and docetaxel neoadjuvant chemotherapy. Ann Oncol 2009; 20: 795-6. [CrossRef]

7. Sezer O, Eucker J, Possinger K. Colitis associated with docetaxel-based chemotherapy. Lancet 2000; 355: 1823-4. [CrossRef]

8. Machado NO. Neutropenic enterocolitis: A continuing medical and surgical challenge. N Am J Med Sci 2010; 2: 293-300

9. Sodhi KS, Aiyappan SK, Singh G, Prakash M, Khandelwal N. Colitis and colonic perforation in a patient with breast carcinoma treated with taxane based chemotherapy. Indian J Cancer 2011; 48: 134-5. [CrossRef]

10. Badgwell BD, Cormier JN, Wray CJ, Borthakur G, Qiao W, Rolston KV, et al. Challenges in surgical management of abdominal pain in the neutropenic cancer patient. Ann Surg 2008; 248: 104-109. [CrossRef] 